\title{
Feasible Momentum Strategies in the US Stock Market*
}

\author{
Manuel Ammann ${ }^{a}$, Marcel Moellenbeck ${ }^{a}$, and Markus M. Schmid ${ }^{\text {b,\# }}$ \\ ${ }^{a}$ Swiss Institute of Banking and Finance, University of St. Gallen, \\ Rosenbergstrasse 52, CH-9000 St. Gallen, Switzerland \\ ${ }^{b}$ University of Mannheim, Finance Area, D-68131 Mannheim, \\ Germany
}

This Version: October 2010

\begin{abstract}
While there is a large literature documenting the profitability of momentum strategies, their implementation is afflicted with many difficulties. Most importantly, high turnover and costs to hold short positions, especially in small-cap stocks, result in high transaction costs. We restrict our investment universe to large-capitalized stocks included in the S\&P 100 index. Moreover, we implement simple investment strategies that invest long in single stocks and short in the stock index. Such simple and cost-saving momentum strategies generate economically high and statistically significant abnormal returns. These results are robust to various risk-adjustments including the CAPM, the Fama French (1993) three-factor model, and a conditional version of the Fama and French (1993) three-factor model.
\end{abstract}

JEL classification: G11, G12

Keywords: Momentum strategies; Large-cap stocks; Stock market predictability

\footnotetext{
* We are grateful to David Rey, Evert Wipplinger, and seminar participants at a joint research workshop of the University of St. Gallen and the University of Konstanz for valuable comments.

\# Corresponding author: Tel.: +49-621-181-37-54; E-mail: schmid@ bwl.uni-mannheim.de. Address: University of Mannheim, Finance Area, Chair for Business Administration and Corporate Governance, D-68131 Mannheim, Germany.
} 


\section{Introduction}

A large body of empirical finance literature documents stock price, continuations, over the intermediate time horizon of three to twelve months and, consequently, the profitability of simple momentum strategies investing in past winners and selling short past losers. In their seminal paper, Jegadeesh and Titman (1993) document that over the time period from 1965 to 1989 past winner stocks continue to outperform past loser stocks on average over a time horizon of three to twelve months by approximately $1 \%$ per year. Chan et al (1996) report comparable profits for momentum strategies based on all stocks listed on NYSE, AMEX, and NASDAQ over the period from January 1977 to January 1993. Jegadeesh and Titman (2001) perform an out-of-sample test of their earlier findings and show that momentum strategies continue to be profitable and past winners outperform past losers by approximately the same magnitude over the time period from 1990 to 1998 as in the earlier period. Rouwenhorst (1998) documents a similar momentum effect for 12 European countries over the period from 1978 to 1995.

There is also evidence that money managers and stock analysts attempt to exploit this pattern of price momentum. Grinblatt et al (1995), for example, examine the quarterly holdings of 274 mutual funds and find that $77 \%$ of the funds in their sample engage in momentum trading. Consistently, Chen et al (2000) document that mutual funds typically buy past winner stocks and sell past loser stocks. Carhart (1997) shows that a one-year momentum effect explains the "hot hands" effect (i.e., the performance persistence) of mutual funds but that individual funds following momentum strategies do not exhibit superior performance. Badrinath and Wahal (2002) show that 1,200 institutions act as momentum traders when they enter stocks but contrarian traders when they exit or make adjustments to ongoing holdings. Finally, Womack (1996) shows that stocks with strong buy recommendations from analysts typi- 
cally exhibit high price momentum, and stocks with strong sell recommendations typically exhibit low price momentum.

To investigate whether momentum strategies can be implemented profitably, trading costs and trading restrictions should be accounted for. Chasing momentum can generate high turnover and much of the potential profits from momentum strategies may be dissipated by transaction costs. Carhart (1997), for example, finds that momentum is not exploitable after transaction costs are taken into account. Grinblatt and Moskowitz (2004) show that a large part of the gains associated with momentum strategies are due to short positions in small and illiquid stocks, leading to high transaction costs. They also find that a large part of momentum profits come from short positions taken in November, anticipating tax-loss selling in December. However, they still conclude that momentum profits are large enough to be economically exploitable. Consistent with Grinblatt and Moskowitz (2004), Ali and Trombley (2006) show that loser stocks rather than winner stocks drive the momentum results. Moreover, they document that the magnitude of momentum returns in the US stock market is related to the short sales constraint determinants identified by D'Avolio (2002) and that stocks with higher short sales constraints exhibit higher momentum returns. Lesmond et al (2004) show that momentum strategies require frequent trading in disproportionately high-cost securities such that trading costs prevent a profitable strategy execution. In the cross-section, they find that those stocks that generate large momentum returns are precisely those stocks with high trading costs. Korajczyk and Sadka (2006) investigate whether momentum strategies are remain profitable after considering market frictions induced by trading. While their findings are consistent with Lesmond et al (2004), they show variations of these strategies, for example liquidity-weighted instead of equally-weighted portfolios, increase the profitability of these strategies after trading costs. 
There are already several attempts to make momentum strategies less expensive with respect to transaction costs. Chan et al (1999) for example restrict their sample to large-cap stocks, Jegadeesh and Titman (2001) exclude stocks with a share price below $\$ 5$, and Grinblatt and Moskowitz (2004) concentrate on long and neglect short positions. Rey and Schmid (2007) even restrict their sample to the largest blue-chip stocks contained in the Swiss Market Index (SMI) and do not invest in decile portfolios but in single stocks. Interestingly, their arbitrage portfolios investing in only one winner and one loser stock by the same time experience annualized average returns of up to $44 \%$, depending on the length of the formation and holding periods. These results are robust to splitting their 11-year sample period ranging from 1994 to 2004 into sub-periods and to different rebalancing schemes. In a recent study, Li et al (2009) analyze the impact of trading costs on the profitability of momentum strategies in the U.K. and show that loser stocks are more expensive to trade than winner stocks. They then test the profitability of low-cost momentum strategies which are restricted to invest in the stocks with the lowest total transaction costs. While their results question the profitability of standard momentum strategies, their low-cost strategies turn out to be profitable after accounting for trading costs.

In this paper, we investigate the returns of simple, low-cost (or 'feasible') momentum strategies in the US stock market. As in Rey and Schmid (2007), we restrict our sample to blue-chip stocks and define the S\&P 100 index as the investment universe. Moreover, we do not invest in decile portfolios but in the single historically best and worst performing stocks. Besides this adjusted version of the original price momentum strategy of Jegadeesh and Titman (1993) proposed by Rey and Schmid (2007), we investigate the profitability of momentum strategies selling short the S\&P 100 index instead of the historically poorest performing loser stocks. In fact, there is evidence that the short positions in loser stocks contribute very little to the overall strategy returns while being mainly responsible for the very high volatility 
of momentum strategies (e.g., Rey and Schmid, 2007). ${ }^{1}$ Moreover, Grinblatt and Moskowitz (2004), Lesmond et al (2004), and Ali and Trombley (2006) show that short positions in small and illiquid stocks are responsible for the high transaction costs associated with the implementation of momentum strategies. Hence, we expect this adjustment to decrease the volatility of our momentum strategies, decrease transaction costs, and potentially increase strategy returns. In addition, we investigate the returns of momentum strategies investing in portfolios consisting of 3,5 , or 10 stocks instead of one single stock.

Our results show that momentum strategies buying the single best performing stock and selling short the S\&P 100 index exhibit monthly mean excess returns of between $1.16 \%$ and $2.05 \%$. When we increase the number of stocks within each investment strand and buy the best 3,5 or 10 stocks instead of the single best performing stock only, the strategy excess returns decrease but remain positive and significant in most cases. Consequently, the momentum effect of blue chip stocks seems to be strongest for the historically very best performing stocks. As compared to the strategies selling short the S\&P 100 index, the returns of strategies selling short the loser stocks are substantially lower and never statistically significant. Overall, we find the strategies investing in only the single best performing stock and selling short the index to exhibit the highest returns. Interestingly, these are also the least expensive strategies as no short sales in individual stocks are necessary.

We apply various measures of risk including a market model, a Fama and French (1993) three-factor model, and a conditional version of the Fama and French (1993) three-factor model based on Ferson and Schadt (1996) and Kat and Miffre (2008). The conditioning information consists of a series of macroeconomic factors including the dividend yield, 3 month interbank rate in the corresponding country, US term spread, and the US default spread. We find our strategy returns to be robust to all these different risk adjustments.

\footnotetext{
${ }^{1}$ In contrast, as indicated above, Grinblatt and Moskowitz (2004) and Ali and Trombley (2006) show that the profitability of momentum strategies stems to a large extent from short positions in small and illiquid stocks.
} 
The remainder of the paper is organized as follows. Section 2 describes the sample and methodology. Section 3 documents the returns of our different momentum strategies. Section 4 assesses the risk and performance of the momentum strategies. In Section 5 we perform a number of robustness checks. Finally, Section 6 concludes.

\section{Sample and Methodology}

We restrict our investment universe to the highly liquid large-cap and blue-chip stocks contained in the S\&P 100 index. To mitigate survivorship bias and assess the "real" (i.e., realizable) historical returns of our single momentum strategies, we exactly replicate the historical composition of the index based on information provided by Standard and Poor's Corp. Consequently, at the time of portfolio rebalancing, the strategies can choose from the effective historical universe of index constituents. For performance calculations we use the companies' total return indices provided by Thomson Reuter's Datastream, which account for dividend payments and adjustments for corporate actions. Hence, we implicitly assume that cash flows resulting from holding positions are reinvested in the corresponding stock. The return data is available from January $1^{\text {st }} 1982$ to December $31^{\text {st }} 2009$ allowing the momentum strategies to start in January 1984.

We use Rey and Schmid's (2007) adjusted version of the original price momentum strategy proposed by Jegadeesh and Titman (1993). Specifically, we calculate each month the past performance over three time horizons of $J=3,6$, and 12 months and sort the shares accordingly. The stocks with the best historical performance are classified as winners and the stocks with the worst performance are classified as losers. Rey and Schmid's (2007) strategies buy one single winner and sell one single loser stock. For our strategies to benefit from diversification effects, we alternatively test strategies buying the best 3,5 , and 10 stocks and selling short the worst 3,5 , and 10 stocks. Additionally we investigate strategies selling the index short instead of individual loser stocks. The examined holding periods, $K$, for all strategies are 
3, 6, and 12 months leading to $K$ individual investment strands with an assigned NAV for each strand.

Jegadeesh (1990), Lehmann (1990), Lo and MacKinlay (1990), and Jegadeesh and Titman (1995) show that for periods up to one month stocks exhibit short-term reversals. Hence, we include a lag of one month between the formation period, over which we calculate the historical stock performance, and the holding period, over which we invest in the identified stocks (or indices) as it is common practice in the literature (e.g., Grundy and Martin, 2001). We require the stocks to provide sufficient historical returns to calculate the relevant past performance for the different strategies over the formation period $J$. As the majority of stocks have already been listed before being included in the S\&P100 index, we use the respective return history prior to inclusion in the S\&P 100 to evaluate past returns.

Following Rey and Schmid (2007), the strategy is implemented according to the following rules. Since the holding period $K$ exceeds the decision frequency (monthly), we have $K$ overlapping investment strands. Such an overlap increases the power of our tests. Each month the positions in one of the $K$ investment strands (the one strand where the holding period elapses) are replaced by the new positions established by the investment rule, while the remaining positions in the other investment strands are left untouched. For the active investment strand, the winners over the last $J$ months are bought and the losers are sold. ${ }^{2}$ The amount invested in the long and short positions at inception is equal to the NAV of the corresponding investment strand. Since the transactions require zero initial investment, we invest the strand's NAV in the money market. In subsequent periods $\mathrm{t}$, the positions established in $\mathrm{t}-K-1$ are sold and new positions based on the ranking in $\mathrm{t}-1$ established. The size of the new positions is de-

\footnotetext{
${ }^{2}$ For example, a strategy with a holding period of $K=3$ months has 3 investment strands. One investment was established 2 months ago and will not be changed for another month. The second investment was established 1 month ago is kept for another 2 months. The position in the third investment strand, which was established 3 months ago, will be divested and its proceeds invested in the stocks and/or index according to the investment rule. This position will then be hold for the next 3 months.
} 
termined by the NAV of the corresponding investment strand. If a winner (loser) stock is already in the portfolio due to previous selection, the winner (loser) is chosen regardless to earn the highest possible momentum premium. To prevent our strategies from possibly being invested in only one stock long and one stock short, we do not allow investments in the same stock by different investment strands in one of our robustness checks, thereby increasing diversification. The sum of the $K$ investment strands represents the overall NAV of the strategy.

Since the strategy does not adjust its total portfolio composition every month, but only the holdings of one investment strand, transaction costs are much lower as compared to momentum strategies that rebalance every month. The drawback is that different investment strands' NAV may develop differently and thus have a widely varying effect on the overall strategy. To dampen the effect, we introduce a yearly rebalancing scheme where the investments funds are distributed evenly over all $K$ investment strands. ${ }^{3}$ If one of the strand's NAV drops below zero, we close this investment strand immediately and rebalance our NAV equally over all $K$ investment strands.

Index adjustments and mergers/acquisitions are treated as follows: A company that drops out of the S\&P 100 but remains listed in the US is held until the end of the holding period. If the company remains listed outside the US only, we sell its stock at the last quoted price in USD and invest the proceeds in the money market until the end of the holding period. In case of stock mergers we accept the take-over bid and hold the new stock. In case of a cash offer, we invest the received compensation in the money market until the end of the holding period.

\section{The Returns of Feasible Momentum Strategies}

Table 1 shows the monthly arithmetic mean returns of momentum strategies with formation periods of $J=3,6$, and 12 months and holding periods of $K=3,6$, and 12 months.

\footnotetext{
${ }^{3}$ The choice of the calendar month does not have a major impact on the results. For the reported strategies, the rebalancing month is July.
} 
These different combinations of formation and holding periods add up to 9 different strategy specifications. Columns 1 to 4 report the returns of strategies with short positions in the S\&P 100 index. Columns 5 to 8 report the returns of strategies with short positions in the individual stocks. The strategies reported in Columns 1 and 5 are based on stock portfolios including the single best (and worst in Column 5) performing stock, Columns 2 and 6 the best (and worst) 3, Columns 3 and 7 the best (and worst) 5, and Columns 4 and 8 the best (and worst) performing 10 stocks.

The results in Column 1, where the long position consists of the historically best performing winner stock and the short position is in the S\&P 100 index, show monthly excess returns between $0.73 \%$ and $1.52 \%$ that are significant at the $10 \%$ level or better with one exception (the $J=3 / K=3$ strategy). Strategies with formation periods of $J=6$ months exhibit the economically highest and statistically most significant abnormal returns, followed by strategies with a formation period of $J=12$ months. For $J=6$ months and $J=12$ months, strategy returns decrease monotonically in the length of the holding period. When we increase the number of stocks within each investment strand and buy the best 3, 5, or 10 stocks instead of the single best performing stock only, the strategies' excess returns drop monotonically in all cases. Hence, the momentum effect in our blue-chip sample seems to be strongest for the very best performing stocks. At the same time, the volatility of the excess returns decreases due to a diversification effect across the investment strands. Hence, the majority of returns of the strategies investing in 3,5 , or 10 individual stocks remain significant at the $5 \%$ or $10 \%$ level despite their lower abnormal returns.

The results in Columns (5) to (8) show that the excess returns of strategies selling short the loser stocks instead of the S\&P 100 index are substantially lower and in some cases even negative. Moreover, the volatility of these strategies is substantially higher indicating that a 
large part of the strategy volatility is due to a high volatility of the loser stocks. As a consequence, there is no significant strategy return observable in Columns (5) to (8).

Figure 1 displays the net asset value (NAV) of the nine momentum strategies based on buying the historically best performing winner stock and selling short the S\&P 100 index as reported in Column 1 of Table 1. Figure 1a displays the three strategy specifications based on a formation period of $J=3$, Figure $1 \mathrm{~b}$ the three strategies with a holding periods of $J=6$, and Figure 1c the three strategies with a holding period of $J=12$. Figure 1a shows that momentum profits pick up in the second half of the sample period. The strategy with a holding period of $K=3$ months earns even negative returns until the end of 1999. Consistently, the strategies based on a formation period of $J=12$ months (Figure 1c) exhibit abnormal returns mainly in the second half of the sample period. Strategies based on a formation of $J=6$ months (Figure 1b) show a constant and steady outperformance over the whole sample period, in particular for holding periods of $K=6$ and $K=12$.

\section{Risk and Performance Analysis}

Table 2 reports risk and performance measures for the momentum strategies buying the best performing individual stock and taking a short position in the index. In addition to the previously reported arithmetic mean returns we show the portfolio volatility, skewness and kurtosis, the Sharpe ratio, the correlation and the beta to the S\&P 100, as well as the CAPM alpha, the alpha from the Fama and French (1993) three factor model and the alphas from two alternative conditional versions of the Fama and French (1993) three-factor models. We obtain the data on the Fama French factors from Kenneth R. French's Data Library.

The volatilities are reported in Column 2 and range from $21.59 \%$ to $34.14 \%$ with decreasing volatility for longer holding periods. For longer holding periods the number of investment cohorts grows and therefore the portfolios exhibit higher diversification. All strategy returns 
are right skewed and the kurtosis ranges from 5.41 to 10.28 indicating leptokurtic distributions. The Sharpe Ratio is between 0.122 and 0.447 and the correlation to the S\&P 100 is positive for all strategies but relatively small ranging from 0.095 to 0.257 . All strategies seem to pick winner stocks with relatively high average betas leading to positive strategy betas between 0.190 and 0.514 . Consequently returns decrease by $0.09 \%$ to $0.24 \%$ when adjusted for market risk. However, five strategies remain significant at the $10 \%$ level or better, whereas three strategies which are significant at the $10 \%$ level in Columns 1 of Table $1(\mathrm{~J}=3 / \mathrm{K}=6$, $J=12 / K=3$, and $J=12 / K=12$ ) drop out of significance. The alphas from a Fama-French 3-factor model reported in Column 9 are comparable to the CAPM-alphas in Column 8. The strategies with a formation period of $J=12$ months and strategy $J=6 / K=12$ have higher Fama-French-alphas than CAPM-alphas (by $0.07 \%$ to $0.22 \%$ ) while the remaining strategies have higher CAPM-alphas as compared to Fama-French-alphas (by $0.03 \%$ to $0.19 \%$ ). Compared to the unadjusted return, in Column 1 the returns of all strategies drop by between $0.01 \%$ and $0.34 \%$, when they are adjusted for systematic risk. However, except for strategy $J$ $=3 / K=6$, all strategies remain statistically significant after adjusting for the three FamaFrench risk factors.

In the spirit of Ferson and Schadt (1996) and Kat and Miffre (2008) we use a conditional risk model where the exposure to the market, the Fama-French returns and the strategies' alphas are conditioned on a set of macroeconomic variables. This approach allows us to investigate whether the risk associated with our momentum strategies is time-varying and depends on the macroeconomic environment. In a dynamic world, risk exposures as well as prices of risks may vary through time and depend on conditioning information. Consistently, Chordia and Shivakumar (2002) and $\mathrm{Wu}$ (2002) show that conditional models are able to explain a large part if not all of momentum profits. In contrast, Griffin et al (2003) find momentum returns to remain largely unaffected when using conditional risk models. Our set of condition- 
ing variables includes the following four variables used in Chordia and Shivakumar (2002) and Griffin et al (2003): the dividend yield, 3 month interbank rate, term spread, and default spread. The excess return of our strategy $r_{t}$ is modeled as follows:

$$
r_{t}=\alpha_{t}+\beta_{t} f_{t}+\varepsilon_{t}
$$

where $f_{t}$ is a vector including the returns of the three Fama-French factors in t. $\alpha_{t}$ and $\beta_{t}$ are the intercept and slope coefficient estimates and $\varepsilon_{\mathrm{t}}$ is the error term.

If $\mathrm{z}_{\mathrm{t}-1}$ represents the set of lagged macroeconomic variables adjusted to have a mean of zero at time t-1, and assuming a linear relationship between our regression parameters and the lagged conditioning information, then the alpha and the betas to the Fama-French factors in the conditional model are equal to:

$$
\begin{aligned}
& \left(\alpha_{t} \mid z_{t-1}\right)=\alpha_{0}+\alpha_{1} z_{t-1} \\
& \left(\beta_{t} \mid z_{t-1}\right)=\beta_{0}+\beta_{1} z_{t-1}
\end{aligned}
$$

Replacing $\alpha_{t}$ and $\beta_{t}$ in (1) by $\left(\alpha_{t} \mid z_{t-1}\right)$ and $\left(\beta_{t} \mid z_{t-1}\right)$ in (2) and (3) yields the following conditional risk model:

$$
r_{t}=\alpha_{0}+\alpha_{1} z_{t-1}+\beta_{0} f_{t}+\beta_{1} f_{t} z_{t-1}+\varepsilon_{t}
$$

The results from this conditional version of the Fama and French (1993) three-factor model are reported in Column 10 and show that the adjusted returns are only slightly reduced as compared to Column 9. Moreover, the returns of five out of nine specifications remain significant while the $J=3 / K=12$ and the $J=12 / K=3$ strategies turn (borderline) insignificant.

\section{Robustness Tests}

As a first robustness check, we omit the annual rebalancing which aims to dampen the effect of widely differing growth rates of the $K$ investment cohorts on strategy performance. Rebalancing now only takes place when an investment strand goes bankrupt. This adjustment 
obviously reduces diversification and introduces more randomness into our strategy. The results are reported in Column 2 of Table 3 and show strongly declining returns for all strategies. ${ }^{4}$ The decrease in strategy returns ranges from $0.04 \%$ to $0.91 \%$. Moreover, the returns of three of the previously eight significant strategies turn insignificant.

The selection procedure described in Section 2 allows our strategies to invest more than one investment strand in the same stock. For example, if in month $t$ the same stock experiences the highest arithmetic mean return over the formation period $J$ as in month $t-1$, two out of $K$ investment sequences are long in the same stock. Column 3 of Table 3 reports the results for momentum strategies that are restricted from investing more than one investment strand in the same stock. Specifically, the strategy buys the second best stock not yet included as a long position in another investment strand. The returns decrease as expected based on the results in Table 1 . However, with the exception of strategy $J=3 / K=12$, all strategy returns remain significant despite a substantial reduction in returns of up to $0.69 \%$.

As a further robustness check, we investigate whether momentum returns are due to a single month with an enormous return value. We do so by dropping the single best return from each strategy's return history and replacing it by zero. The magnitude of the reduction in terms of arithmetic mean returns is between $0.12 \%$ and $0.16 \%$ and does not change our results qualitatively. Therefore, to save space, we do not report the results in a table.

Transaction costs can reduce the profitability of investment strategies considerably. Lesmond et al (2004) find that momentum strategies lead to trades in disproportionally high cost securities and the profits vanish if adequate transaction costs are introduced. By construction we avoid investing in stocks with cost-intensive transactions and our short positions can be efficiently established with future contracts.

\footnotetext{
${ }^{4}$ Column 1 reproduces the results in Column 1 of Table 1 for ease of comparison.
} 
Grundy and Martin (2001) find for their momentum profits that a roundtrip cost above $1.50 \%$ leads to insignificant results and a $1.77 \%$ roundtrip cost drives the profits to zero. To assess the impact of transaction costs on our strategy returns, we account for transaction costs by subtracting them from the NAV at the time of occurrence. Transaction costs are quoted relative to turnover in percentage of the traded position size and are applied to each buy and each sell activity. Therefore, the roundtrip costs are equal to two times the stated costs. The most profitable strategy $(J=6 / K=3)$ remains significant at the $10 \%$ level if we include transaction costs of up to 75 basis points (i.e., roundtrip costs of 150 basis points). The strategies' mean return becomes zero if transaction costs increase to 193 basis points. The $J=6$ / $K$ $=12$ strategy's mean return turns insignificant when transaction costs equal 133 basis points and equals zero when transaction costs amount to 316 basis points. The higher value of transaction costs for the $J=6 / K=12$ strategy despite the weaker performance is due to the horizon of the holding period. A trading strategy holding assets for three months in each investment strand trades almost 4 times as much as a strategy holding the assets for 12 months. As an example of a strategy with an intermediate holding period, e.g., the strategy $J=6 / K=6$, we find strategy mean returns to remain significant at the $10 \%$ level when transaction costs are below 111 basis points. The return remains positive as long as transaction costs are lower than 271 basis points. To save space we do not report the full set of results in a table. Overall, we find that transaction costs of $0.2 \%$ lead to a decrease in monthly profits by 15.76 to 15.88 bp for strategies with holding period $K=3$, by 9.77 to $9.83 \mathrm{bp}$ for strategies with holding period $K=6$, and by 6.75 to 6.81 bp for strategies with holding period $K=12$.

Finally we investigate whether there is a specific pattern in the seasonality of momentum returns. Figure 2 displays the arithmetic mean returns in each calendar month for the strategies reported in Column 1 of Table 1. Overall there seems to be no clear pattern and the returns to our feasible momentum strategies do not seem to accrue in one specific month only. 
For most strategies June and November to January were the best performing months in the observed time period. July, August, and October were the worst performing months with most strategies showing negative returns.

\section{Conclusion}

This study measures the profitability of feasible momentum strategies in the US stock market designed for a minimization of trading costs. Therefore, our investment universe is restricted to the large-cap stocks included in the Standard and Poor's 100 index. We find evidence for economically and statistically significant returns for strategies investing long in the single best performing stock and selling short the index instead of individual stocks. These results are consistent with Griffin et al (2005) who show that mainly long portfolio contributes to momentum profits. Our results are also in line with Grinblatt and Moskowitz (2004) who show that small-cap returns are the main driver for abnormal returns generated by the short portfolio. As our strategies are restricted from trading small-cap stocks, we would expect that our short portfolio does not contribute to the strategy returns.

We apply various measures of risk including a market model, a Fama and French (1993) three-factor model, and a conditional version of the three-factor model based on Ferson and Schadt (1996) and Kat and Miffre (2008). We find our strategy returns, where positive and significant, to be only slightly reduced on a risk-adjusted basis. 


\section{References}

Ali, A. and Trombley, M.A. (2006) Short sales constraints and momentum in stock returns. Journal of Business Finance \& Accounting 33: 587-615.

Badrinath, S.G. and Wahal, S. (2002) Momentum trading by institutions. Journal of Finance 57: 2449-2478.

Carhart, M.M. (1997) On persistence in mutual fund performance. Journal of Finance 52: 5782.

Chan, K.C.L., Jegadeesh, N. and Lakonishok, J. (1996) Momentum strategies. Journal of Finance 51: 1681-1713.

Chan, K.C.L., Jegadeesh, N. and Lakonishok, J. (1999) The profitability of momentum strategies. Financial Analysts Journal 55: 80-90.

Chen, H.-L., Jegadeesh, N. and Wermers, R. (2000) The value of active mutual fund management: An examination of the stockholdings and trades of fund managers. Journal of Financial and Quantitative Analysis 35: 343-368.

Chordia, T., and Shivakumar, L. (2002) Momentum, business cycle, and time-varying expected returns. Journal of Finance 57: 985-1019.

D'Avolio, G. (2002) The market for borrowing stock. Journal of Financial Economics 66: 271-306.

Fama, E.F. and French, K.R. (1993) Common risk factors in the returns on stocks and bonds. Journal of Financial Economics 33: 3-56.

Fama, E.F. and French, K.R. (1996) Multifactor explanations of asset pricing anomalies. Journal of Finance 51: 55-84.

Ferson, W. and Schadt R. (1996) Measuring fund strategy and performance in changing economic conditions. Journal of Finance 51: 425-461.

Griffin, J.M., Xiuqing, J. and Spencer, M.J. (2003) Momentum investing and business cycle risk: Evidence from pole to pole. Journal of Finance 58: 2515-2547.

Griffin, J.M., Xiuqing, J. and Spencer, M.J. (2005) Global momentum strategies. Journal of Portfolio Management 31: 23-39.

Grinblatt, M. and Moskowitz, T.J. (2004) Predicting stock price movements from past returns: The role of consistency and tax-loss selling. Journal of Financial Economics 71: 541579. 
Grinblatt, M., Titman, S. and Wermers, R. (1995) Momentum investment strategies, portfolio performance and herding: A study of mutual fund behavior. American Economic Review 85: $1088-1105$.

Grundy, B.D. and Martin, J.S. (2001) Understanding the nature of the risks and the source of the rewards to momentum investing. Review of Financial Studies 14: 29-78.

Jegadeesh, N. (1990) Evidence of predictable behavior of security returns. Journal of Finance 45: 881-898.

Jegadeesh, N. and Titman, S. (1993) Returns to buying winners and selling losers: Implications for stock market efficiency. Journal of Finance 48: 65-91.

Jegadeesh, N. and Titman, S. (1995) Overreaction, delayed reaction, and contrarian profits. Review of Financial Studies 8: 973-993.

Jegadeesh, N. and Titman, S. (2001) Profitability of momentum strategies: An evaluation of alternative explanations. Journal of Finance 56: 699-720.

Korajczyk, R.A. and Sadka, R. (2006) Are momentum profits robust to trading costs? Journal of Finance 59: 1039-1082.

Lehmann, B.N. (1990) Fads, martingales, and market efficiency. Quarterly Journal of Economics 60: 1-28.

Lesmond, D.A., Schill, M.J. and Zhou, C. (2004) The illusory nature of momentum profits. Journal of Financial Economics 71: 349-380.

Li, X., Brooks, C. and Miffre, J. (2009) Low-cost momentum strategies. Journal of Asset Management 9: 366-379.

Lo, A.W. and MacKinlay, A.C. (1990) When are contrarian profits due to stock market overreaction? Review of Financial Studies 3: 175-205.

Kat, H.M. and Miffre, J. (2008) The impact of non-normality risks and tactical trading on hedge fund alphas. Journal of Alternative Investments 10: 8-21.

Rey, D.M. and Schmid, M.M. (2007) Feasible momentum strategies: Evidence from the Swiss stock market. Financial Markets and Portfolio Management 21: 325-352.

Rouwenhorst, K.G. (1998) International momentum strategies. Journal of Finance 53: 267284.

Wu, X. (2002) A conditional multifactor analysis of return momentum. Journal of Banking and Finance 26: 1675-1696. 
Table 1: Monthly arithmetic mean returns of S\&P 100 momentum strategies, 1984 - 2009

\begin{tabular}{|c|c|c|c|c|c|c|c|c|c|}
\hline \multirow{2}{*}{\multicolumn{2}{|c|}{$\begin{array}{c}\text { Number of } \\
\text { shares }\end{array}$}} & \multicolumn{4}{|c|}{ Index short } & \multicolumn{4}{|c|}{ Stock short } \\
\hline & & \multirow{2}{*}{$\begin{array}{c}1 \\
(1)\end{array}$} & \multirow{2}{*}{$\begin{array}{c}3 \\
(2) \\
\end{array}$} & \multirow{2}{*}{$\begin{array}{c}5 \\
(3) \\
\end{array}$} & \multirow{2}{*}{$\begin{array}{l}10 \\
(4) \\
\end{array}$} & \multirow{2}{*}{$\begin{array}{c}1 \\
(5) \\
\end{array}$} & \multirow{2}{*}{$\begin{array}{c}3 \\
(6) \\
\end{array}$} & \multirow{2}{*}{$\begin{array}{c}5 \\
(7) \\
\end{array}$} & \multirow{2}{*}{$\begin{array}{l}10 \\
(8) \\
\end{array}$} \\
\hline$\underline{J}$ & $K$ & & & & & & & & \\
\hline \multirow[t]{2}{*}{3} & 3 & $0.80 \%$ & $0.24 \%$ & $0.07 \%$ & $0.02 \%$ & $0.07 \%$ & $-0.25 \%$ & $-0.20 \%$ & $-0.29 \%$ \\
\hline & & $(0.1492)$ & $(0.4900)$ & $(0.7942)$ & $(0.9376)$ & $(0.9314)$ & $(0.6334)$ & $(0.6610)$ & $(0.4281)$ \\
\hline \multirow[t]{2}{*}{3} & 6 & $0.73 \% *$ & $0.39 \%$ & $0.26 \%$ & $0.18 \%$ & $0.18 \%$ & $-0.01 \%$ & $0.08 \%$ & $0.04 \%$ \\
\hline & & $(0.0732)$ & $(0.1805)$ & $(0.2916)$ & $(0.3083)$ & $(0.7771)$ & $(0.9814)$ & $(0.8261)$ & $(0.8786)$ \\
\hline \multirow[t]{2}{*}{3} & 12 & $0.84 \% * *$ & $0.53 \% * *$ & $0.38 \% *$ & $0.28 \% *$ & $0.04 \%$ & $0.10 \%$ & $0.08 \%$ & $0.10 \%$ \\
\hline & & $(0.0178)$ & $(0.0285)$ & $(0.0699)$ & $(0.0639)$ & $(0.9362)$ & $(0.7458)$ & $(0.7645)$ & $(0.6451)$ \\
\hline \multirow[t]{2}{*}{6} & 3 & $1.52 \% * * *$ & $0.61 \% *$ & $0.37 \%$ & $0.30 \%$ & $0.54 \%$ & $0.55 \%$ & $0.30 \%$ & $0.17 \%$ \\
\hline & & $(0.0068)$ & $(0.0695)$ & $(0.1930)$ & $(0.1595)$ & $(0.5700)$ & $(0.3784)$ & $(0.5598)$ & $(0.6650)$ \\
\hline \multirow[t]{2}{*}{6} & 6 & $1.33 \% * * *$ & $0.71 \% * *$ & $0.51 \% * *$ & $0.41 \% * *$ & $0.23 \%$ & $0.39 \%$ & $0.33 \%$ & $0.38 \%$ \\
\hline & & $(0.0054)$ & $(0.0174)$ & $(0.0440)$ & $(0.0316)$ & $(0.7938)$ & $(0.4722)$ & $(0.4586)$ & $(0.2725)$ \\
\hline \multirow[t]{2}{*}{6} & 12 & $1.08 \% * * *$ & $0.58 \% * *$ & $0.44 \% * *$ & $0.40 \% * *$ & $0.06 \%$ & $0.12 \%$ & $0.27 \%$ & $0.29 \%$ \\
\hline & & $(0.0048)$ & $(0.0232)$ & $(0.0424)$ & $(0.0168)$ & $(0.9286)$ & $(0.7809)$ & $(0.4449)$ & $(0.3063)$ \\
\hline \multirow[t]{2}{*}{12} & 3 & $1.15 \% * *$ & $0.76 \% * *$ & $0.58 \% *$ & $0.50 \% * *$ & $-0.46 \%$ & $0.34 \%$ & $0.55 \%$ & $0.52 \%$ \\
\hline & & $(0.0404)$ & $(0.0438)$ & $(0.0620)$ & $(0.0327)$ & $(0.6503)$ & $(0.6004)$ & $(0.2973)$ & $(0.2271)$ \\
\hline \multirow[t]{2}{*}{12} & 6 & $1.11 \% * *$ & $0.65 \% *$ & $0.58 \% *$ & $0.48 \% * *$ & $-0.31 \%$ & $0.25 \%$ & $0.49 \%$ & $0.48 \%$ \\
\hline & & $(0.0307)$ & $(0.0701)$ & $(0.0514)$ & $(0.0344)$ & $(0.7389)$ & $(0.6732)$ & $(0.3224)$ & $(0.2309)$ \\
\hline \multirow[t]{2}{*}{12} & 12 & $0.91 \% *$ & $0.44 \%$ & $0.40 \%$ & $0.37 \% *$ & $-0.60 \%$ & $-0.08 \%$ & $0.08 \%$ & $0.15 \%$ \\
\hline & & $(0.0540)$ & $(0.1732)$ & $(0.1298)$ & $(0.0643)$ & $(0.4489)$ & $(0.8766)$ & $(0.8426)$ & $(0.6507)$ \\
\hline
\end{tabular}

The table reports monthly arithmetic mean returns of S\&P 100 momentum strategies for different combinations of formation period $J$ and holding period $K$. Each investment strand invests in the best performing $1,3,5$, and 10 stocks over the respective formation period and enters a short position of equal size in the S\&P 100 index (Columns 1 to 4 ) or the worst performing 1, 3, 5, and 10 stocks (Columns 5 to 8). 'Number of shares' indicates the number of winner stocks bought in each column (and similarly the number of loser stocks sold short in Columns 5 to 8 ). As the long and short positions are cash neutral at inception, the capital is invested in the money market. There is a one-month lag between the holding and formation period. At the start of the strategy and once every year, the available capital is evenly distributed to the $K$ investment strands of each strategy. The sample period covers the 26-year period from January 1984 to December 2009. $p$-values (in parentheses) are based on a standard $t$-test. $* * * * *, *$ denotes statistical significance at the $1 \%, 5 \%, 10 \%$ level. 
Table 2: Risk and performance analysis

\begin{tabular}{|c|c|c|c|c|c|c|c|c|c|c|c|}
\hline$J$ & $K$ & $\begin{array}{l}\text { Arithmetic } \\
\text { Mean Return } \\
\text { (monthly) } \\
(1)\end{array}$ & $\begin{array}{c}\text { Volatility } \\
\text { (annually) } \\
(2)\end{array}$ & $\begin{array}{c}\text { Skewness } \\
\text { (monthly) } \\
\text { (3) }\end{array}$ & $\begin{array}{l}\text { Kurtosis } \\
\text { (monthly) } \\
(4)\end{array}$ & $\begin{array}{c}\text { Sharpe } \\
\text { Ratio } \\
\text { (annually) } \\
(5)\end{array}$ & $\begin{array}{l}\text { Correlation } \\
\text { S\&P 100 } \\
\text { (monthly) } \\
(6)\end{array}$ & $\begin{array}{c}\text { Beta } \\
\text { S\&P 100 } \\
\text { (monthly) } \\
(7)\end{array}$ & $\begin{array}{l}\text { CAPM Alpha } \\
\text { (monthly) } \\
(8)\end{array}$ & $\begin{array}{c}\text { Fama French } \\
\text { Alpha } \\
\text { (monthly) } \\
\text { (9) }\end{array}$ & $\begin{array}{l}\text { Conditional } \\
\text { Model (4 Pred } \\
\text { Variables) } \\
\text { Alpha } \\
\text { (monthly) } \\
(10)\end{array}$ \\
\hline 3 & 3 & $\begin{array}{r}0.80 \% \\
(0.1492)\end{array}$ & $9.74 \%$ & 0.90 & 7.59 & 0.122 & 0.149 & 2.273 & $\begin{array}{r}0.64 \% \\
(0.2305)\end{array}$ & $\begin{array}{r}0.45 \% \\
(0.3803)\end{array}$ & $\begin{array}{r}0.48 \% \\
(0.2777)\end{array}$ \\
\hline 3 & 6 & $\begin{array}{c}0.73 \% * \\
(0.0732)\end{array}$ & $7.20 \%$ & 1.23 & 8.35 & 0.234 & 0.153 & 2.651 & $\begin{array}{r}0.62 \% \\
(0.1568)\end{array}$ & $\begin{array}{r}0.48 \% \\
(0.2099)\end{array}$ & $\begin{array}{r}0.35 \% \\
(0.3114)\end{array}$ \\
\hline 3 & 12 & $\begin{array}{l}0.84 \% \text { ** } \\
(0.0178)\end{array}$ & $6.23 \%$ & 1.50 & 10.28 & 0.366 & 0.203 & 3.492 & $\begin{array}{c}0.71 \% * \\
(0.0539)\end{array}$ & $\begin{array}{l}0.65 \% * * \\
(0.0434)\end{array}$ & $\begin{array}{r}0.42 \% \\
(0.1291)\end{array}$ \\
\hline 6 & 3 & $\begin{array}{l}1.52 \% * * * \\
(0.0068)\end{array}$ & $9.85 \%$ & 0.89 & 5.89 & 0.373 & 0.095 & 1.724 & $\begin{array}{l}1.42 \% * * * \\
(0.0093)\end{array}$ & $\begin{array}{l}1.35 \% * * * \\
(0.0095)\end{array}$ & $\begin{array}{l}1.28 \% * * \\
(0.0155)\end{array}$ \\
\hline 6 & 6 & $\begin{array}{l}1.33 \% \text { *** } \\
(0.0054)\end{array}$ & $8.36 \%$ & 0.89 & 6.36 & 0.411 & 0.100 & 1.613 & $\begin{array}{l}1.24 \% * * * \\
(0.0057)\end{array}$ & $\begin{array}{l}1.21 \% * * * \\
(0.0042)\end{array}$ & $\begin{array}{l}1.02 \% * * \\
(0.0175)\end{array}$ \\
\hline 6 & 12 & $\begin{array}{l}1.08 \% \text { *** } \\
(0.0048)\end{array}$ & $6.68 \%$ & 0.89 & 6.85 & 0.447 & 0.225 & 4.040 & $\begin{array}{c}0.92 \% * * \\
(0.0114)\end{array}$ & $\begin{array}{l}1.03 \% * * * \\
(0.0024)\end{array}$ & $\begin{array}{l}0.83 \% * * * \\
(0.0085)\end{array}$ \\
\hline 12 & 3 & $\begin{array}{l}1.15 \% * * \\
(0.0404)\end{array}$ & $9.84 \%$ & 0.91 & 5.58 & 0.242 & 0.213 & 3.595 & $\begin{array}{r}0.93 \% \\
(0.1013)\end{array}$ & $\begin{array}{c}0.99 \% * \\
(0.0655)\end{array}$ & $\begin{array}{r}0.82 \% \\
(0.1326)\end{array}$ \\
\hline 12 & 6 & $\begin{array}{l}1.11 \% * * \\
(0.0307)\end{array}$ & $9.06 \%$ & 0.72 & 5.41 & 0.275 & 0.257 & 4.217 & $\begin{array}{c}0.87 \% * \\
(0.0845)\end{array}$ & $\begin{array}{l}1.05 \% * * \\
(0.0250)\end{array}$ & $\begin{array}{c}0.91 \% * \\
(0.0510)\end{array}$ \\
\hline 12 & 12 & $\begin{array}{c}0.91 \% * \\
(0.0540)\end{array}$ & $8.31 \%$ & 0.82 & 6.41 & 0.241 & 0.261 & 4.769 & $\begin{array}{r}0.68 \% \\
(0.1322)\end{array}$ & $\begin{array}{l}0.90 \% * * \\
(0.0251)\end{array}$ & $\begin{array}{c}0.73 \% * \\
(0.0544)\end{array}$ \\
\hline
\end{tabular}

The table reports risk and performance measures for S\&P 100 momentum strategies buying the single best performing stock and selling short the S\&P 100 index as reported in Column (1) of Table 1. For ease of comparison, Column (1) in this table reproduces the arithmetic excess mean returns of the nine strategies as reported in Column (1) of Table 1. Column (2) reports the annualized volatility of the strategies, Columns (3) and (4) the skewness and kurtosis, Column 5 the Sharpe Ratio calculated as the strategy excess return divided by the volatility, Columns (6) the correlation with the S\&P 100 index, and Column (7) the beta obtained by regressing the strategy returns on the S\&P 100 index returns. Column (8) reports CAPM-alpha where the S\&P 100 index is used as a market proxy. Column (9) reports the alpha from a Fama and French (1993) three-factor model including the excess return of the S\&P 100 index, the Fama-French SMBfactor, and the Fama-French HML-factor as risk factors. Column (10) reports the alphas from a conditional version of the Fama and French (1993) three-factor model. The conditioning factors are the dividend yield, 3 month interbank rate, term spread, and default spread. All regression $p$-Values are Newey-West adjusted. The sample period includes the 26 years from January 1984 to December 2009. $p$-values (in parentheses) are based on a standard $t$-test. ***,**, denotes statistical significance at the $1 \%, 5 \%, 10 \%$ level. 


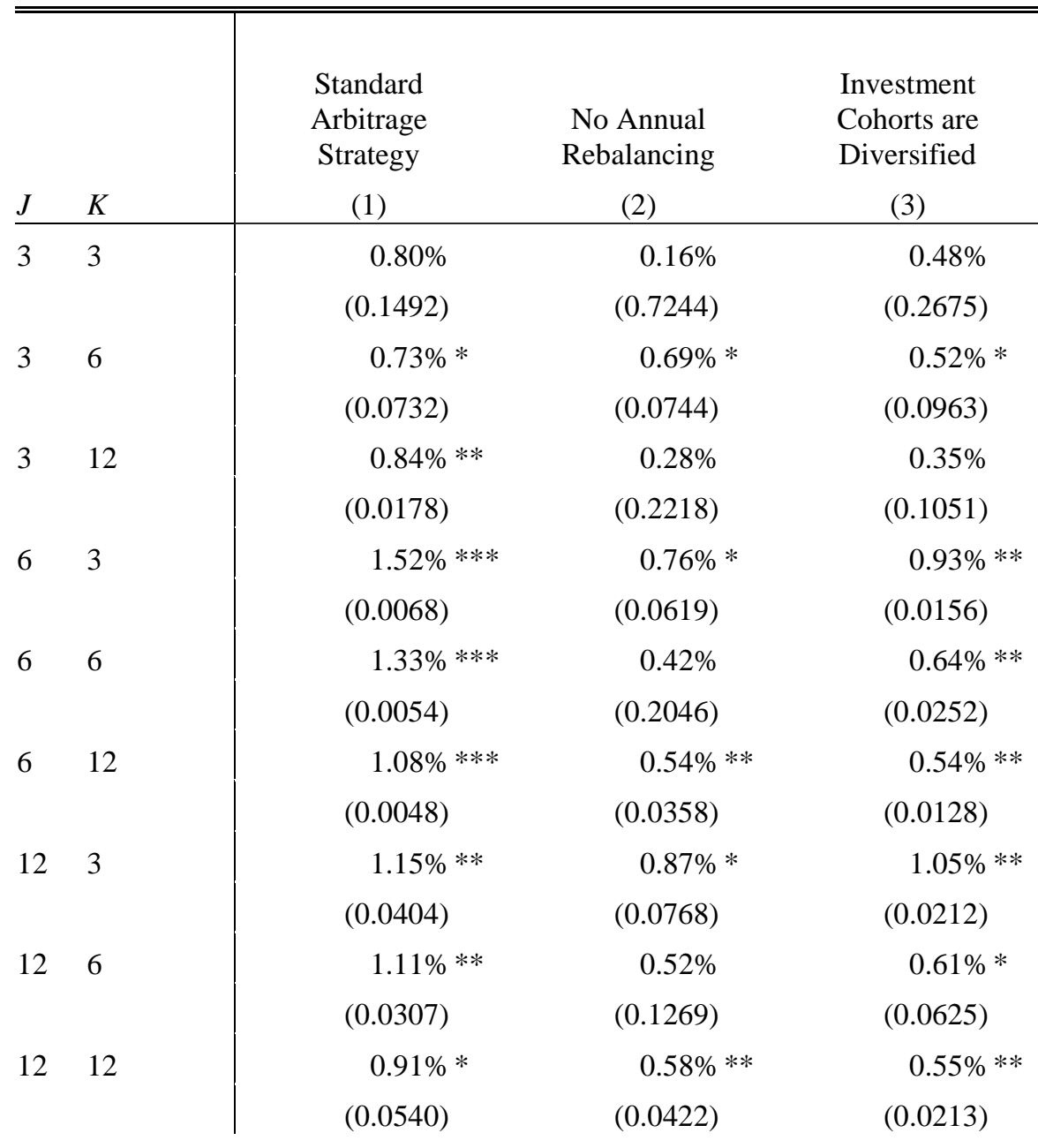

The table reports the monthly arithmetic mean returns of the S\&P 100 momentum strategies buying the single best performing stock and selling short the S\&P 100 index when the annual rebalancing is omitted (Column 2) and when the strategy is restricted from investing more than one investment strand in the same stock (Column 3). For ease of comparison, Column (1) in this table reproduces the arithmetic mean returns as reported in Column 1 of Table 1 . The sample period covers the 26 years from January 1984 to December 2009. $p$-values are reported in parentheses and based on a standard $t$-test. $* * *, * * *$ denotes statistical significance at the $1 \%$, $5 \%$, and $10 \%$ level. 
Figure 1: Strategy NAV

Figure 1a: Formation Period $J=3$ months

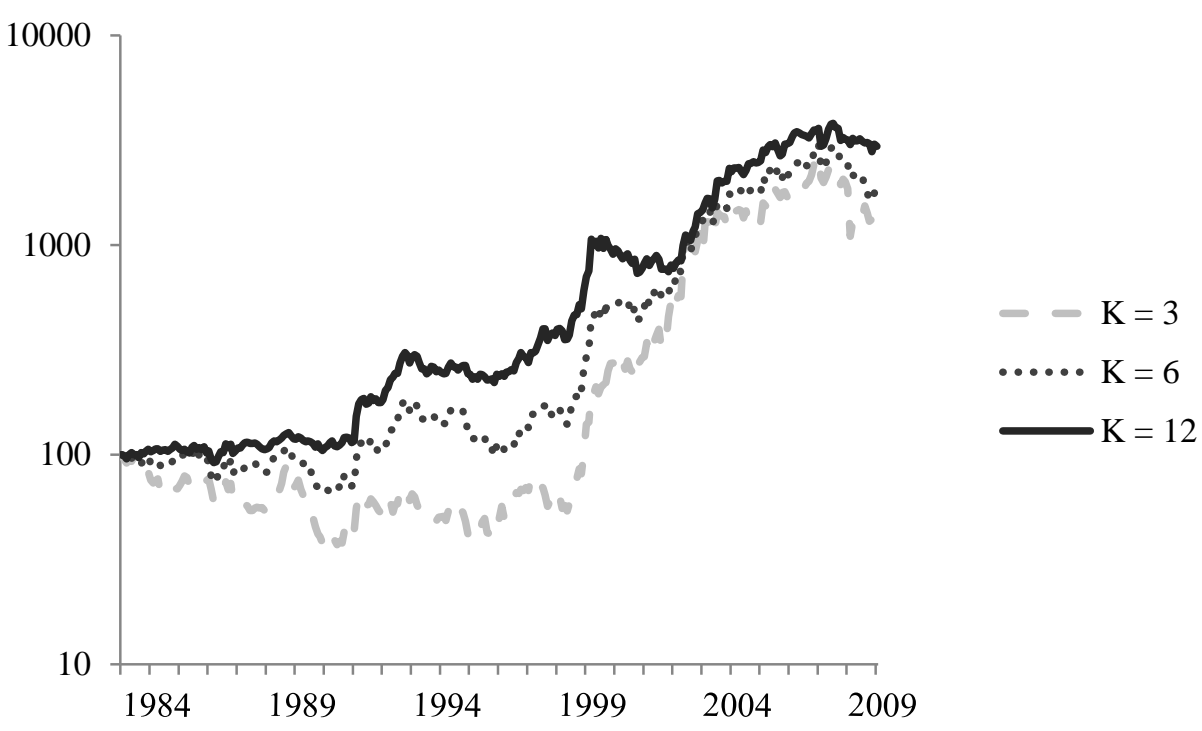

Figure 1b: Formation Period $J=6$ months

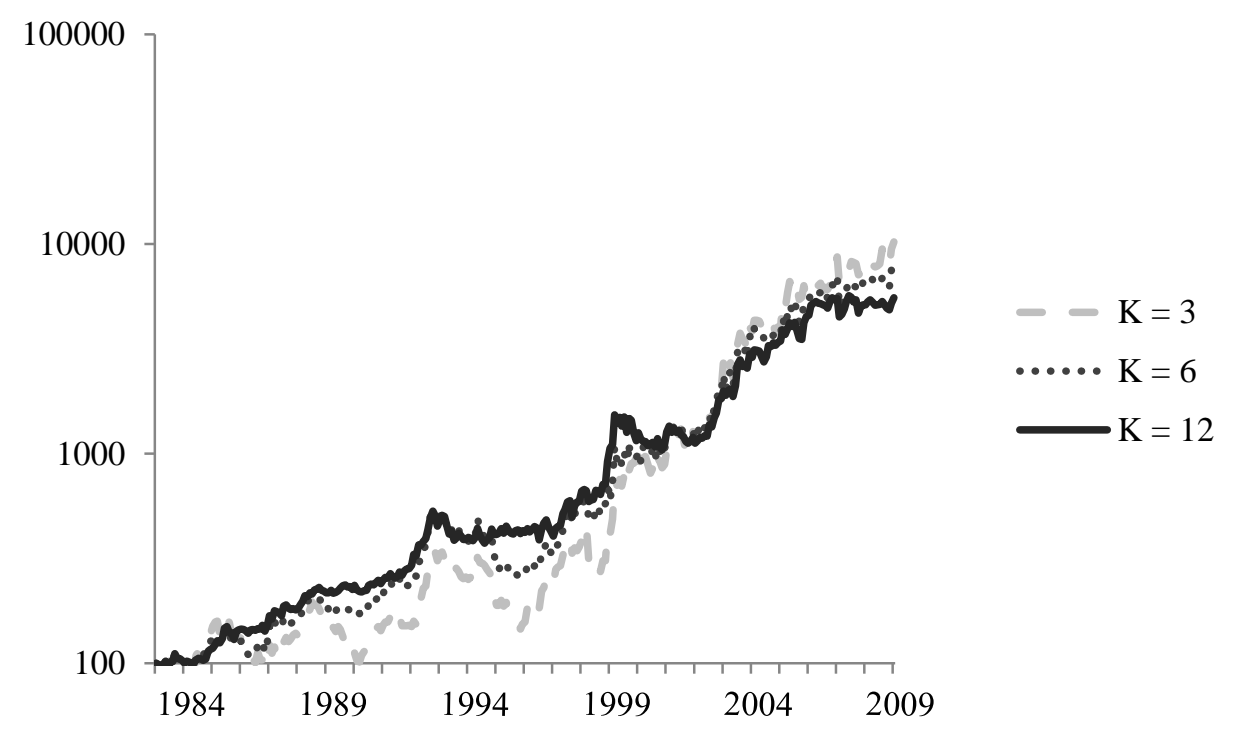


Figure 1c: Formation Period $J=12$ months

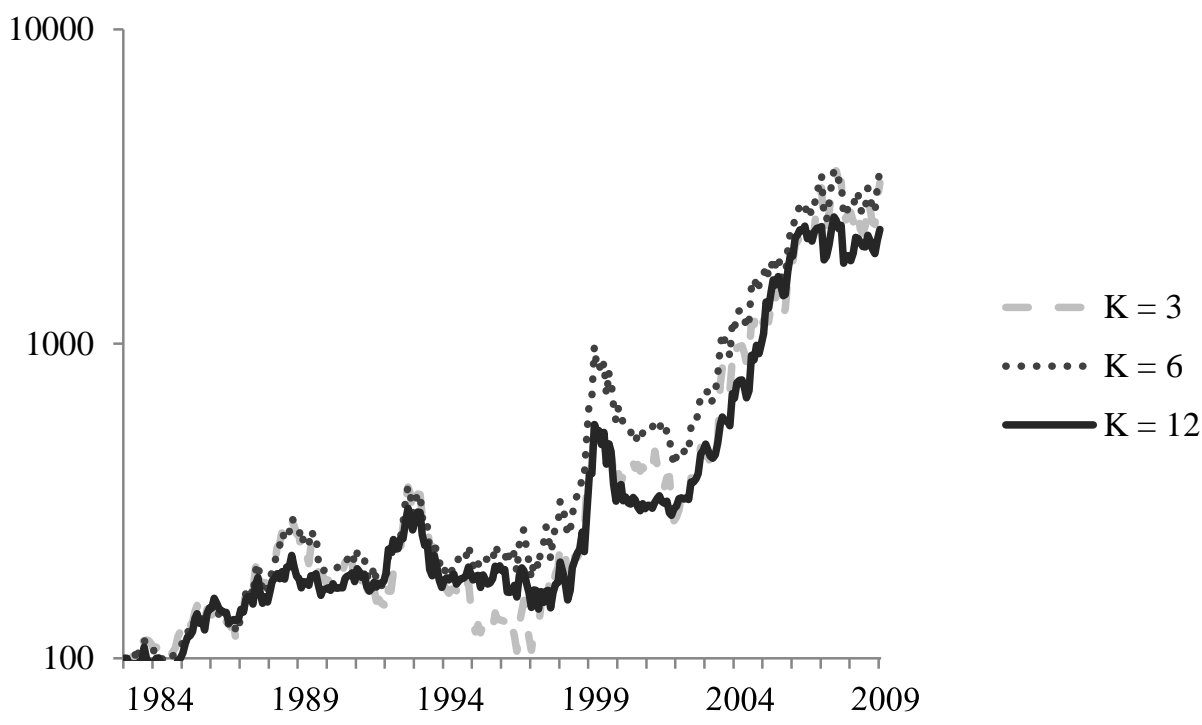

The figure displays the NAV of the nine momentum strategies buying the single best winner stock and selling short the S\&P 100 index over the time period from 1984 to 2009 as reported in Column 1 of Table 1 (logarithmic scale). The $K$ different investment strands are rebalanced annually. Figure 1a displays the three strategies with a formation period of $J=3$ and holding periods, $K$ of 3,6 , and 12 months. Figure $1 \mathrm{~b}$ displays the three strategies with a holding period of $J=6$ months and Figure 1c the three strategies with a holding period of $J$ $=12$ months. 
Figure 2: Strategy mean returns for each calendar month

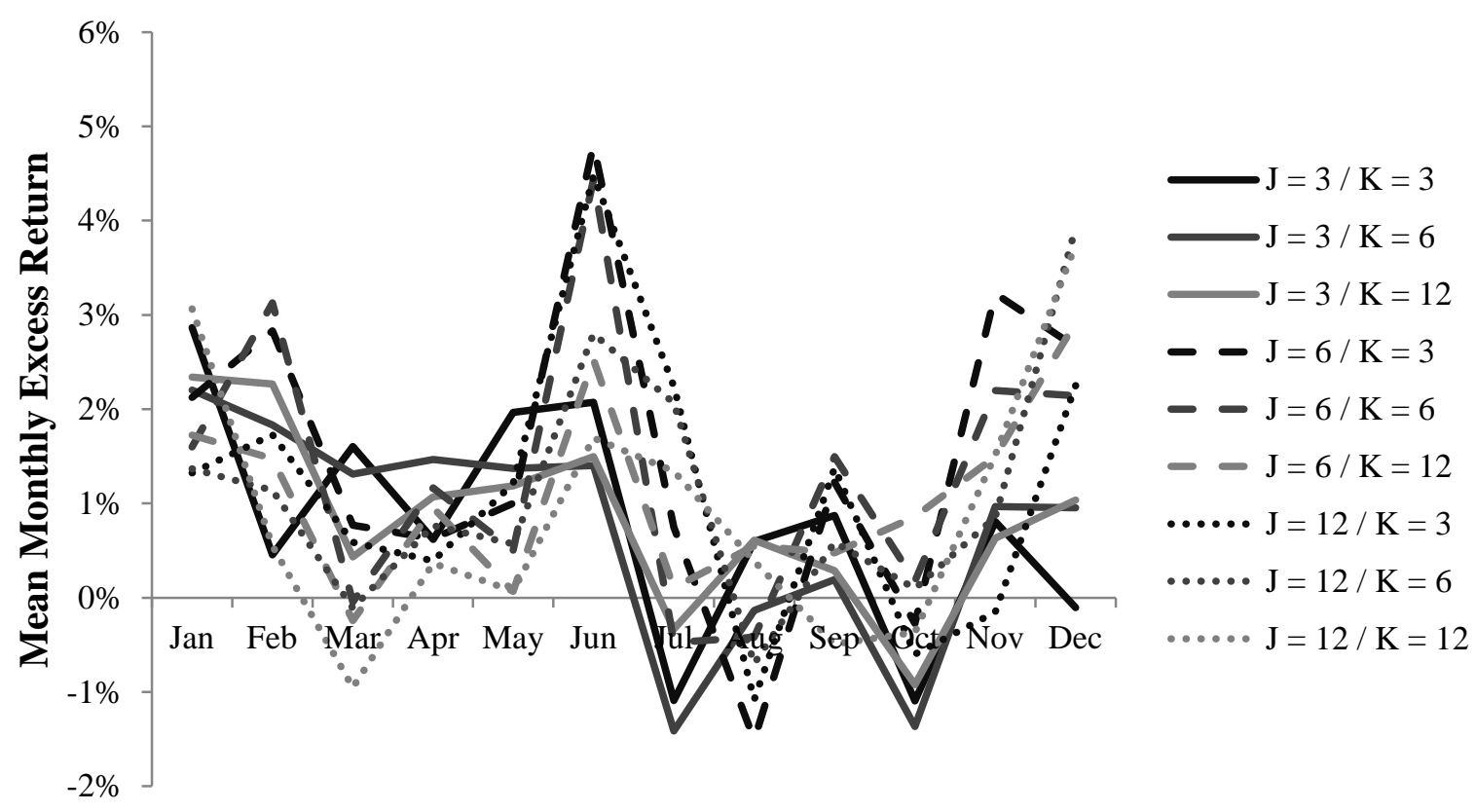

The figure reports the monthly arithmetic mean returns for all nine $J$ and $K$ combinations of the momentum strategies buying the historically best performing winner stock and selling short the S\&P 100 index (as reported in Column 1 of Table 1) for each calendar month separately. 